\title{
QUEEN'S
UNIVERSITY
BELFAST
}

\section{Fine-scale hydrodynamic metrics underlying predator occupancy patterns in tidal stream environments}

Lieber, L., Nimmo-Smith, W. A. M., Waggitt, J. J., \& Kregting, L. (2018). Fine-scale hydrodynamic metrics underlying predator occupancy patterns in tidal stream environments. Ecological Indicators, 94(1), 307-408. https://doi.org/10.1016/j.ecolind.2018.06.071

\section{Published in:}

Ecological Indicators

\section{Document Version:}

Peer reviewed version

Queen's University Belfast - Research Portal:

Link to publication record in Queen's University Belfast Research Portal

\section{Publisher rights}

(C) 2018 Elsevier Ltd.

This work is made available online in accordance with the publisher's policies. Please refer to any applicable terms of use of the publisher.

\section{General rights}

Copyright for the publications made accessible via the Queen's University Belfast Research Portal is retained by the author(s) and / or other copyright owners and it is a condition of accessing these publications that users recognise and abide by the legal requirements associated with these rights.

Take down policy

The Research Portal is Queen's institutional repository that provides access to Queen's research output. Every effort has been made to ensure that content in the Research Portal does not infringe any person's rights, or applicable UK laws. If you discover content in the Research Portal that you believe breaches copyright or violates any law, please contact openaccess@qub.ac.uk. 
1 Fine-scale hydrodynamic metrics underlying predator occupancy patterns in 2 tidal stream environments

3

$4 \quad$ Lilian Lieber ${ }^{*}$, W. Alex M. Nimmo-Smith², James J. Waggitt ${ }^{3}$, Louise Kregting ${ }^{1}$

5

$6{ }^{1}$ School of Natural and Built Environment, Queen's University Marine Laboratory, 12-13 The Strand,

$7 \quad$ Portaferry, BT22 1PF, Northern Ireland, UK

$8 \quad{ }^{2}$ Marine Institute, University of Plymouth, Drake Circus, Plymouth, PL4 8AA, England, UK

$9{ }^{3}$ School of Ocean Sciences, Bangor University, Menai Bridge, Anglesey, LL59 5AB, UK

10

$11 *$ Corresponding author:

12 Lilian Lieber

13 Queen's University Marine Laboratory

$14 \quad$ 12-13 The Strand

15 Portaferry BT22 1PF

16 Northern Ireland, UK

17 Email: l.lieber@qub.ac.uk

18 Tel: 0044 (0) 2842727806

19

20 
Whilst the development of the tidal stream industry will help meet marine renewable energy (MRE) targets, the potential impacts on mobile marine predators using these highly dynamic environments need consideration. Environmental impact assessments (EIAs) required for potential MRE sites generally involve site-specific animal density estimates obtained from lengthy and costly surveys. Recent studies indicate that whilst large-scale tidal forcing is predictable, local hydrodynamics are variable and often result in spatio-temporal patchiness of marine predators. Therefore, understanding how fine-scale hydrodynamics influence animal distribution patterns could inform the placing of devices to reduce collision and displacement risks. Quantifying distributions requires animal at-sea locations and the concurrent collection of high-resolution hydrodynamic measurements. As the latter are routinely collected during tidal resource characterization at potential MRE sites, there is an untapped opportunity to efficiently collect information on the former to improve EIAs. Here we describe a survey approach that uses vessel-mounted ADCP (Acoustic Doppler current profiler) transects in combination with marine mammal surveys to collect high-resolution and concurrent hydrodynamic data in relation to pinniped (harbour seals Phoca vitulina, grey seals Halichoerus grypus) at-sea occupancy patterns within an energetic tidal channel (peak current magnitudes $>4.5 \mathrm{~ms}^{-1}$ ). We identified novel ADCP-derived fine-scale hydrodynamic metrics that could have ecological relevance for seals using these habitats. We show that our local acoustic backscattering strength metric (an indicator for macro-turbulence) had the highest influence on seal encounters. During peak flows, pinnipeds avoided the mid-channel characterized by extreme backscatter. At-sea occupancy further corresponded with the increased shear and eddies that are strong relative to the mean flows found at the edges of the channel. Our approach, providing oceanographic context to animal habitat use through combined survey methodologies, enhances environmental management of potential MRE sites. The cost-effective collection of such data and the application of our metrics could streamline the EIA process in the early stages of the consenting process.

Keywords: Acoustic Doppler current profiler, acoustic backscatter, physical drivers, environmental impact assessment, marine renewable energy, pinniped 


\section{Introduction}

The global drive towards marine renewable energy (MRE) extraction has led to a rapid increase in planned tidal turbine installations in coastal areas experiencing high $\left(>2 \mathrm{~ms}^{-1}\right)$ current speeds (Fraenkel 2004). Whilst the exploitation of tidal stream energy will help reach renewable energy targets, the potential impacts on animals using these habitats must be considered in recognition of marine licensing and legislation. A variety of mobile marine predators (cetaceans, pinnipeds, seabirds) exploit tidally energetic environments for foraging opportunities (Benjamins et al., 2015a). However, there is still a large degree of uncertainty surrounding interactions between predators and tidal devices. A range of potential impacts have been identified including collisions with moving components, displacement from foraging areas and changes in foraging efficiency and locomotive costs due to possible alteration of flow fields around array installations (Shields et al. 2011; Fox et al., 2017). To protect against these risks, environmental impact assessments (EIA) are generally required in the consenting process, where potential risks are identified, and mitigation measures established before developments commence. In many parts of the world, developers are tasked by regulators to undertake marine mammal site characterizations (e.g. boat-, plane- or shorebased surveys) as part of EIAs (Wilson et al., 2007; Savidge et al., 2014). These surveys are aimed at generating baseline data of marine mammal presence to eventually derive site-specific absolute abundance or density estimates (Benjamins et al., 2015b). However, despite the high cost and time involved in these surveys, the density estimates generally have high levels of uncertainty due to the complexity of ecological systems (Harwood and Stokes, 2003).

A different approach is to understand how animals use these energetic tidal environments in relation to hydrodynamic forcing and fine-scale variations in vertical profiles. Flow regimes are not homogenous in tidal environments and vary owing to the occurrence of fine-scale, tidally-driven or bathymetry-induced physical processes, including shear boundaries, eddies and boils (Nimmo-Smith et al., 1999; Evans et al., 2013; Jones et al., 2014; Kregting et al., 2016). This heterogeneity creates spatial and temporal variation in the distribution of species, with marine predators regularly 
associated with certain tidal velocities and physical processes (Johnston et al., 2005; Embling et al., 2012; Jones et al., 2014; Waggitt et al., 2016a; Waggitt et al., 2016b; Benjamins et al., 2016; Benjamins et al., 2017). Therefore, quantifying spatio-temporal variation in animal site usage in relation to hydrodynamic features may help to identify which and when areas may be used (Zamon 2001; Waggitt \& Scott 2014; Benjamins et al., 2015b; Hastie et al., 2016; Waggitt et al., 2017a). This can provide developers with valuable information prior to array installation to reduce the risk of collision and displacement. This information can also predict changes in distributions caused by potential alterations in the hydrodynamic regime around installations (Shields et al. 2011). Tidal resource characterization generally marks the early stages of an MRE project to quantify the physical properties of the site, estimate potential energy generation and evaluate the placing of devices (Polagye \& Thomson 2013). Acoustic Doppler current profilers (ADCPs) are instruments designed to measure current velocities (speed and direction) and flow structures throughout the water column and are widely used during MRE resource characterization to capture the local flow dynamics over a range of spatial and temporal scales (Evans et al., 2013). ADCPs can either be bottom-mounted to measure a flow's temporal variation at a specific location (Lu \& Lueck 1999), or vessel-mounted to infer spatial variation in velocities across a site (Simpson et al., 1990). To capture fine-scale spatial heterogeneity, it has been demonstrated that vessel-mounted ADCP surveys can provide valuable means to characterize tidal energy sites, overcoming the need to deploy high-resolution grids of moored ADCPs across a site (Fong \& Monismith 2004; Epler et al., 2010; Evans et al., 2013; Goddijn-Murphy et al., 2013; Savidge et al., 2014). 

species known to exhibit tidal patterns in their distributions (harbour seals Phoca vitulina and grey seals Halichoerus grypus) in relation to concurrently collected, high-resolution hydrodynamic data. The study was performed in a highly dynamic, restricted tidal channel located in Strangford Lough, Northern Ireland. Characterized by depth-averaged current magnitudes exceeding $4 \mathrm{~ms}^{-1}$ during spring tides, the channel is frequently exploited as a tidal turbine test site (Jeffcoate et al., 2016). Using vessel-mounted ADCP transects, data were collected during a spring and neap tidal cycle to fulfil two main objectives. Firstly, we sought to measure high-resolution spatial and temporal variations in hydrodynamic conditions to visualize and quantify novel fine-scale metrics of physical processes to provide oceanographic context to animal site usage (macro-turbulence, eddies and shear). Secondly, to test the ecological relevance of these metrics by comparing their explanatory power to inform at-sea pinniped distributions to that of more commonly-used measurements in tidal stream environments (current magnitude, depth and time to high water).

\section{Material and Methods}

\subsection{Study site}

The survey was performed within the Narrows, a tidal channel linking Strangford Lough to the Irish Sea, located on the east coast of Northern Ireland, UK (Fig. 1). The Narrows are approximately $8 \mathrm{~km}$ long with a minimum width of $1 \mathrm{~km}$ and depth varying between $30-60 \mathrm{~m}$ in the depth contour. 


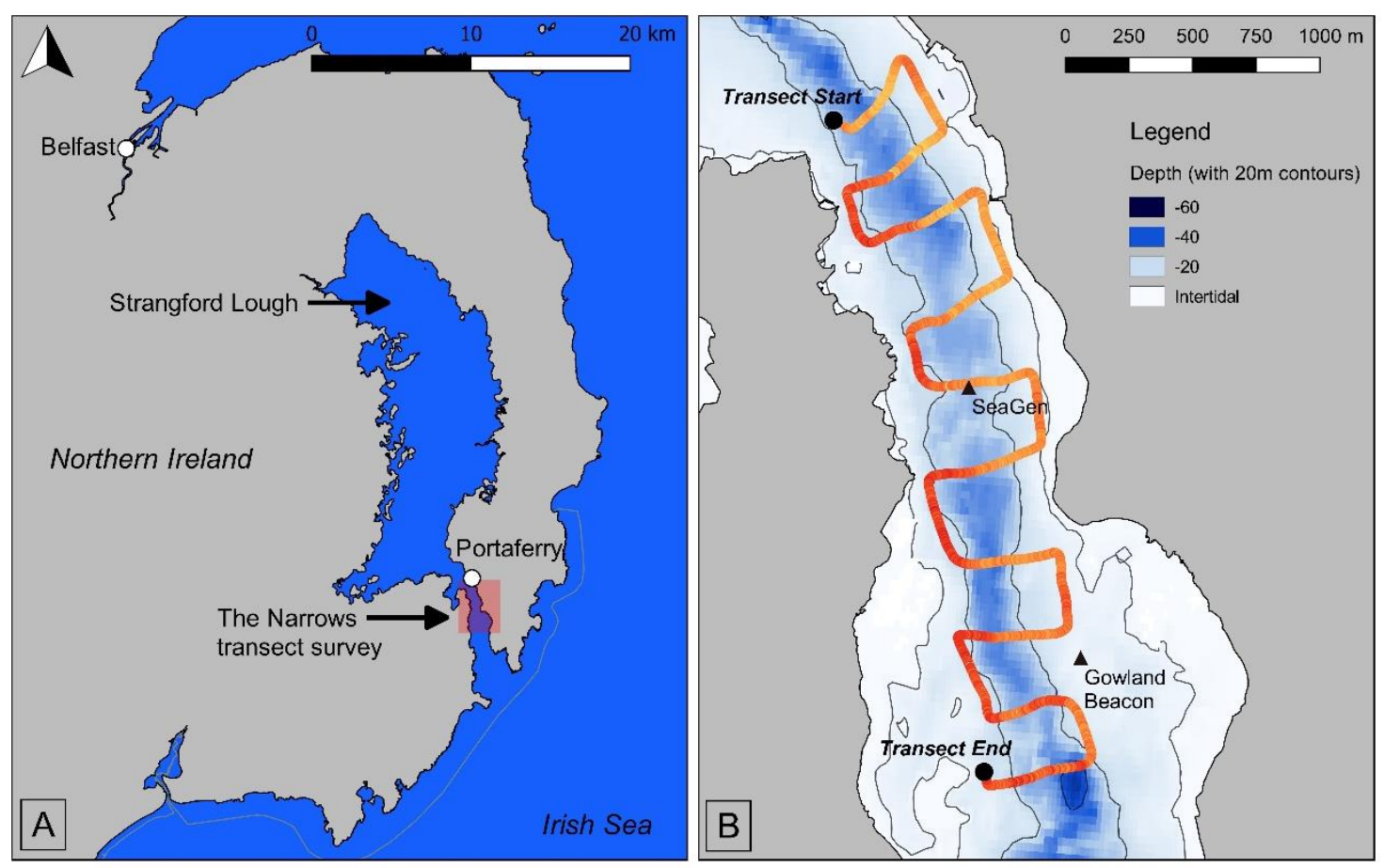

Figure 1: (A) Map showing the study area within the Narrows, a tidal channel located in Strangford Lough, Northern

Ireland, UK, highlighted by a red box. (B) Path of a representative vessel-mounted ADCP transect (Transect 1, 20 October

2016) performed within the Narrows colored by ADCP-derived sea surface temperature $\left({ }^{\circ} \mathrm{C}\right)$. Note, small cross-channel variation in temperatures $\left(\min =13.18^{\circ} \mathrm{C}\right.$, yellow; $\max =13.98^{\circ} \mathrm{C}$, red) are visible due to different rates of advection and vertical mixing.

Data were collected over two semi-diurnal tidal cycles (approximately 12 hours per cycle) during a spring (progression from springs to neaps) and a neap (progression from neaps to springs) tide on October $20^{\text {th }}$ and $28^{\text {th }} 2016$, respectively (Fig.2). Strangford Lough is a designated Special Area of Conservation, with the harbour seal, listed on Annex II of the EC Habitats Directive, presenting a qualifying feature. The study was conducted following the species' breeding and moulting season (timings vary but $P$. vitulina pupping is generally in June/July, with moulting thereafter in July/August). During the time of the survey, the UK's first full-scale tidal turbine, SeaGen, installed in the Narrows in 2008 , was non-operational and there were no other turbines under test within the area covered by transects. 

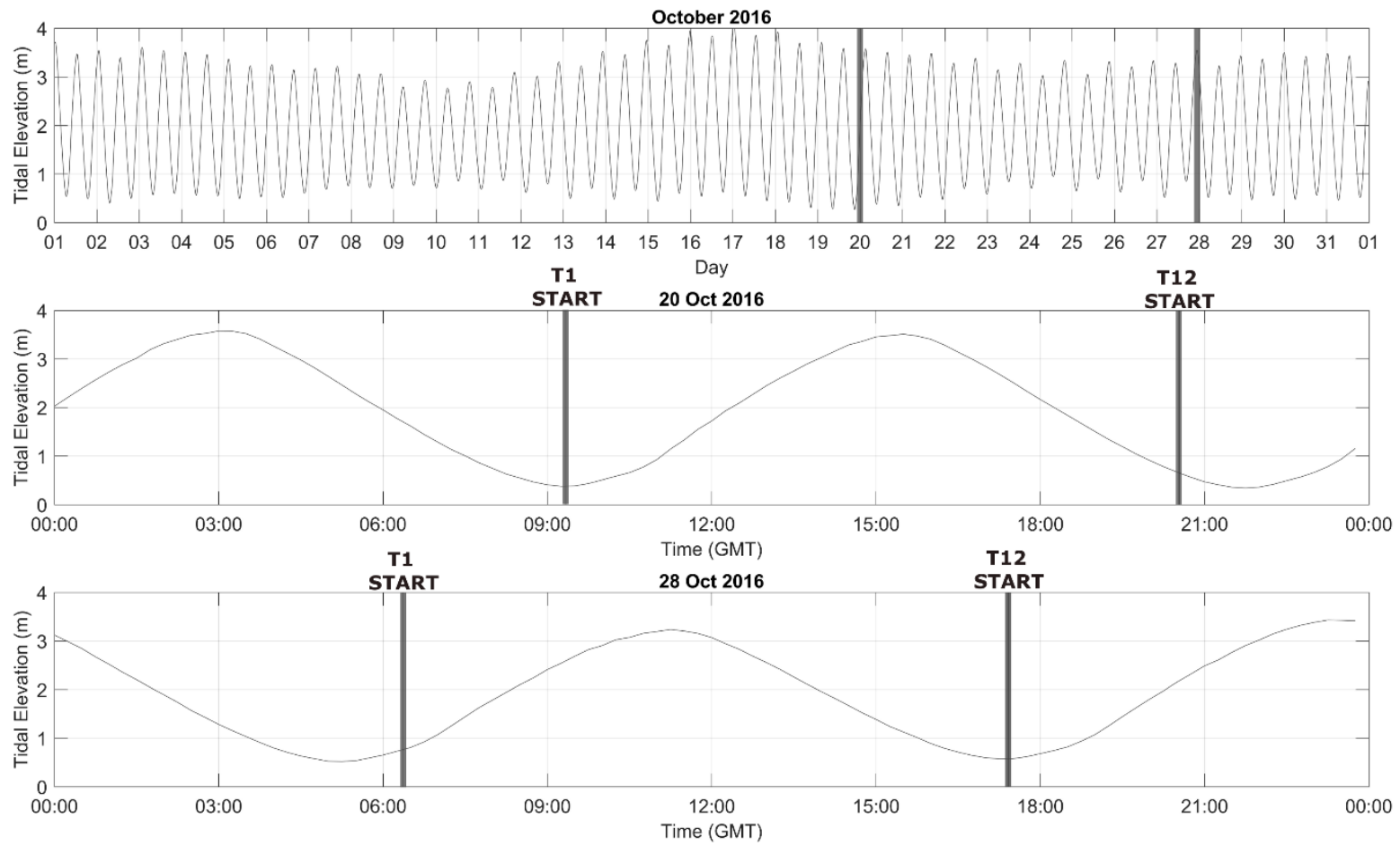

Figure 2: Tidal regime shown for the month of October 2016 from a tide gauge located at Portaferry Pier (top panel) with lines highlighting the spring and neap tidal survey days on 20 and 28 October 2016, respectively. The middle and bottom panel show the semi-diurnal tidal cycle during each survey, with grey lines marking the start of Transect 1 and 12 (T1; T12) for each survey day.

\subsection{Transect design}

Repeat parallel-line transects were performed onboard a 10.5m long offshore-coded vessel

(The Cuan Shore, Cuan Marine Services Ltd) travelling at a constant vessel speed of 5 knots, during a sea state of 0-1 and a visibility of 6-10km (Fig. 1). This setup allowed for controlled vessel movement and comparable data acquisition conditions across surveys. Transects were run perpendicular to the dominant flow direction and made up of square, parallel transect lines rather than zig zag lines to 1 ) maximize coverage across the varying current fields, 2) better identify small-scale hydrodynamic features along the edges of the channel, and 3) avoid an overestimation in velocity in the direction of the boat (Fong \& Monismith 2004). A total of 24 transects (240 lines) were performed where each transect started from the same point and consisted of 10 lines (each line $=\sim 450 \mathrm{~m}$ ) at $\sim 300 \mathrm{~m}$ spacing, covering an approximate area of $2900 \mathrm{~m} \times 450 \mathrm{~m}$ (along-track distance $=\sim 7000 \mathrm{~m}$ ). Transects 
were repeated 12 times at hourly intervals over a tidal period starting at low water on 20 October 2016 and one hour after low water on 28 October 2016 (Fig. 2).

\subsection{CTD and tidal elevation}

To assess stratification and the speed of sound in the Narrows, twelve conductivity-

temperature-depth (CTD) profiles were collected throughout the neap survey day, 28 October 2016,

using a Valeport CTD (model 602) at the start and end of every second transect in the mid-channel

(Table S1, Supplementary Information). Tidal elevation data was extracted from a monitoring (>3 months) tide gauge located at the Portaferry Pier in the Narrows, Strangford Lough.

\subsection{Acoustic Doppler Current Profiler (ADCP) collection and post-processing} used for the transect surveys. The ADCP was mounted on the starboard side of the vessel at $1.15 \mathrm{~m}$ depth with its sensors checked and internal compass calibrated on the boat prior to the survey. The ADCP's operating frequency was $600 \mathrm{kHz}$ and it was configured to ping at $1 \mathrm{~Hz}$ with an ensemble interval of 1 second and a vertical bin size (cell depth size of averaged data) of $1 \mathrm{~m}$ (ambiguity velocity=3.8 m/s). An on-board differential GPS system (Hemisphere) was linked to the incoming ADCP data stream acquired with VMDas software (v. 1.46; RD Instruments, Inc.) to provide navigational information during transects.

As part of the standard quality control procedures, ADCP data was post-processed in

WinADCP (v. 1.14; RD Instruments, Inc.) using default parameters for vertical, horizontal and error velocities, percent good pings, beam correlation, and surface or bottom reflection; and data was checked for anomalous pitch and roll. True water velocities were computed by subtraction of the bottom-tracked boat velocity. Depth-averaged velocity vectors were plotted over transect lines to visualize areas of variable flow such as eddies and flow reversals. These were then quantified as 'Relative Variance in Velocity' (Re/VarVel), a bin-averaged (horizontally and vertically) velocity covariate later used in modelling. For this, within 1 min-binned time intervals along a given transect, 
the sum of the standard deviation of the depth-averaged northward and eastward velocity components was divided by mean current magnitude, resulting in a parameter describing the horizontal variance in current velocity relative to the strength of the flow at the given location. This parameter increases in variable weak flows (relatively strong eddies in areas of low currents). Further, vertical shear $(\mathrm{S})$ was calculated across $1 \mathrm{~m}$ vertical intervals along each transect using the following equation:

$$
\mathrm{S}=\left((\mathrm{du} / \mathrm{dz})^{2}+(\mathrm{dv} / \mathrm{dz})^{2}\right)^{1 / 2}
$$

where $d u / d z$ and $d v / d z$ are the vertical gradients in the east and the north velocity components, respectively.

High values of scattering, or echo intensity, can be associated with zooplankton, fish, suspended sediment or turbulence, such as enhanced surface bubble entrainment indicative of macro-turbulence (Brierley et al., 1998; Nimmo-Smith et al., 1999; Demer et al., 2000; Lavery et al., 2009). In tidal channels, it is likely that the scattering source is dominated by the latter. Therefore, to quantify the acoustic scattering in the water column as a metric for macro-turbulence, volumebackscattering strength ( $\mathrm{Sv}$, measured in decibels, $\mathrm{dB}$ ) was calculated over a finite volume (maximum of 40 bins) from the ADCP's recorded raw echo intensity data using a working version of the sonar equation as described in Deines (1999). Sv has been evaluated separately for each bin along each of the four beams of the ADCP. For each range bin, the maximum of the four beams $\left(S v_{\max }\right)$ was taken to create depth profiles of the maximum level of scattering through the water column.

\subsection{Marine mammal transect survey design}

Constant effort (continuous search effort) surveys for marine mammals were conducted throughout eight of the 12 transects (omitting hours of darkness) during both survey days with resting times in between transects (when steaming back to the starting point) to avoid observer fatigue. Observations were made from the front deck of the vessel ( $3 \mathrm{~m}$ above water level), capturing 
a $300 \mathrm{~m}$-wide transect on either side $\left( \pm 90^{\circ}\right)$ and ahead of the vessel. Sightings were made by the naked eye and identified to species level using binoculars when required. Time and position of sightings were recorded using a handheld GPS (Garmin GPSMAP 78). The relative bearing in degrees $\left.{ }^{\circ}\right)$ from the vessel was noted using mounted angle boards, and radial distance to the animal was estimated by eye with the help of available landmarks and the use of rangefinder binoculars. Environmental data (sea state and visibility) were recorded at the start of each new transect or when conditions changed. A total transect distance of $117.23 \mathrm{~km}$ was covered during the marine mammal surveys, with an average transect length of $7.33 \mathrm{~km}(S D=322.58 \mathrm{~m})$. Overall observer effort comprised 11.4 hours with an average transect duration of $43 \mathrm{~min}(\mathrm{SD}=5.26 \mathrm{~min})$. The sighting data reported in this study present a measure of relative sea usage rather than absolute numbers or densities. Further, the number of independent observations was insufficient to apply the detection function to obtain robust animal density estimates (Buckland et al. 2001; Thomas et al. 2010).

\subsection{Marine mammal data analysis}

Generalized additive models (GAMs: Wood 2006) with a binomial error distribution and a 'logit' link function were used to quantify the relationship between the probability of encountering a seal (grey or harbour) and hydrodynamic measurements. GAMs construct a series of polynomial curves showing quantifying relationships between the response and explanatory variables, with each polynomial curve focusing upon a different range of the explanatory variable. over different ranges of the latter. These polynomial curves are joined together at a series of locations known as knots, enabling non-linear relationships between explanatory and response variables to be quantified. As non-linear relationships were expected, GAMs were preferred over Generalized Linear Models (GLM) (Wood, 2006).

Combinations of current direction, speed and depth indirectly detect the presence of hydrodynamic features. For instance, turbulent-structures often occur in shallow and fast-water in the wake of islands/headlands (Benjamins et al., 2015). However, the ADCP-derived measurements 
should directly detect these hydrodynamic features. Statistical analyses investigated whether directmeasurements of turbulent structures were better at explaining variance in the presence of seals than indirect-measurements of these hydrodynamic features. Two different sets of models were performed. The first set of models consisted of three explanatory variables commonly used to explain animal distributions in tidal stream environments (e.g. Hastie et al., 2016; Waggitt et al., 2016a): time to high tide ( $M 2 H T)$, depth-averaged current magnitude (Mag) and depth. These explanatory variables were combined in a single model. Backwards model selection was performed thereafter, with only significant $(p<0.05)$ explanatory variables retained in the final model (Zuur 2010). The second set of models used novel explanatory variables derived from concurrent ADCP measurements: backscattering strength $\left(S v_{\max }\right)$, mean relative variance in velocity (Re/VarVel) and maximum shear (MaxS). As these explanatory variables quantify similar hydrodynamic features, shown by strong collinearity (Fig. S1, Supplementary Information), these were modelled separately. This approach allowed the performance of each novel explanatory variable to be directly compared to the set of more conventional explanatory variables. The number of knots was constrained to 3 to avoid overfitting and test for ecologically interpretable relationships (Waggitt et al. 2016b). The exception was $M 2 H T$ where the number of knots was constrained to 6 , as more complicated relationships were expected across the ebb-flood cycle. Distance $(m)$ travelled per minute was also included as an offset to account for differences in the area covered among samples. Further information on response and explanatory variables is provided below. GAMs were performed in R (v.3.1.1; R Core Team 2013) using the 'mgcv' package (v. 1.8-12; Woods 2017). The response variable was the presence or absence of seals per minute. Rather than simply matching the timing of the sighting (Presence) to the ADCP 1-minute bin-averaged period, the positional data point of the sighting (corrected for distance and bearing) was taken and matched to the nearest bottom-tracked latitude/longitude waypoint along the transect (spatial rather than temporal matching). This was done by calculating the distance from the sighting to all waypoints along the track and finding the nearest distance. This approach is more robust than temporal 
matching by extracting the physically nearest environmental parameters experienced by the seal. This provided the highest resolution match in space because seals were often seen prior to the vessel's closest point of approach to the seal's position.

The explanatory variables were the mean or maximum values of hydrodynamic water column measurements per minute. The mean was calculated for water depth (in meters), time to high tide (in minutes), depth-averaged current magnitude (in meters per second) and relative variance in velocity (Re/VarVel, in meters per second); the maximum values of vertical shear and volume backscattering strength $\left(S_{v}\right.$ in $\left.\mathrm{dB} r e 1 \mathrm{~m}^{-1}\right)$ were calculated per minute. The use of maximum rather than mean values meant that fine-scale, but prominent hydrodynamic features associated with high vertical shear and backscattering strength would be identified. All explanatory variables were modelled as non-linear terms.

Residuals showed no evidence of spatial or temporal autocorrelation, so additional statistical approaches to account for this (e.g. mixed effect models, general estimating equations) were deemed unnecessary. Relationships between the probability of encountering seals and each explanatory variable were then estimated from model parameters. In these estimations, the explanatory variable of interest was varied between its minimum and maximum value, whilst others were held at their mean value. An effect size was obtained by dividing the absolute difference between the minimum and maximum predicted values by the minimum predicted value. The calculation of a standardized effect size allowed the relative influence of different explanatory variables to be directly compared (Waggitt et al., 2017b). This standardized effect size was then used to compare the relative influence of explanatory variables.

\section{Results}

\subsection{Hydrodynamics}

Contour plots of an entire transect during minimum flow velocities (slack low water, transect 1; Fig. 3a) and as a comparison, at times of maximum flow velocities (peak flood, transect 4; Fig. 3b), are given for two representative time-series during the spring tide survey. Throughout the ADCP 
transects, higher current speeds were recorded during the flooding tide compared to the ebbing tide, as well as during the spring survey compared to the neap survey. This is in accordance with the asymmetry of the tidal cycle (shorter flood, and longer ebb periods, respectively) and hydrodynamic model predictions (Kregting \& Elsäßer 2014). Generally, strongest flow velocities were recorded in the central parts of the channel compared to the edges, with pronounced fine-scale variability in tidal velocity, shear and acoustic backscatter (a metric for macro-turbulence) as a response to the channel's bathymetry (Fig. 3b). Patches of high vertical shear were found near the bed in the central part of the channel associated with the strongest flows there, but also in regions of rapidly changing bathymetry towards the sides of the main channel, over the $20 \mathrm{~m}$ depth contour. 
a)

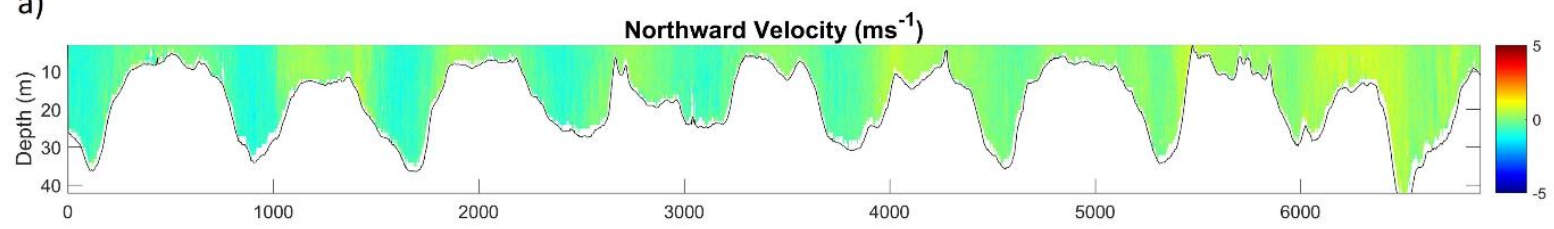

Eastward Velocity $\left(\mathrm{ms}^{-1}\right)$

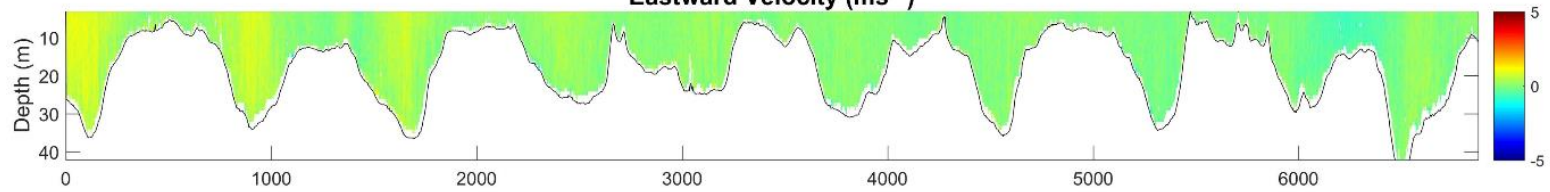

Shear $\left(\mathrm{s}^{-1}\right)$
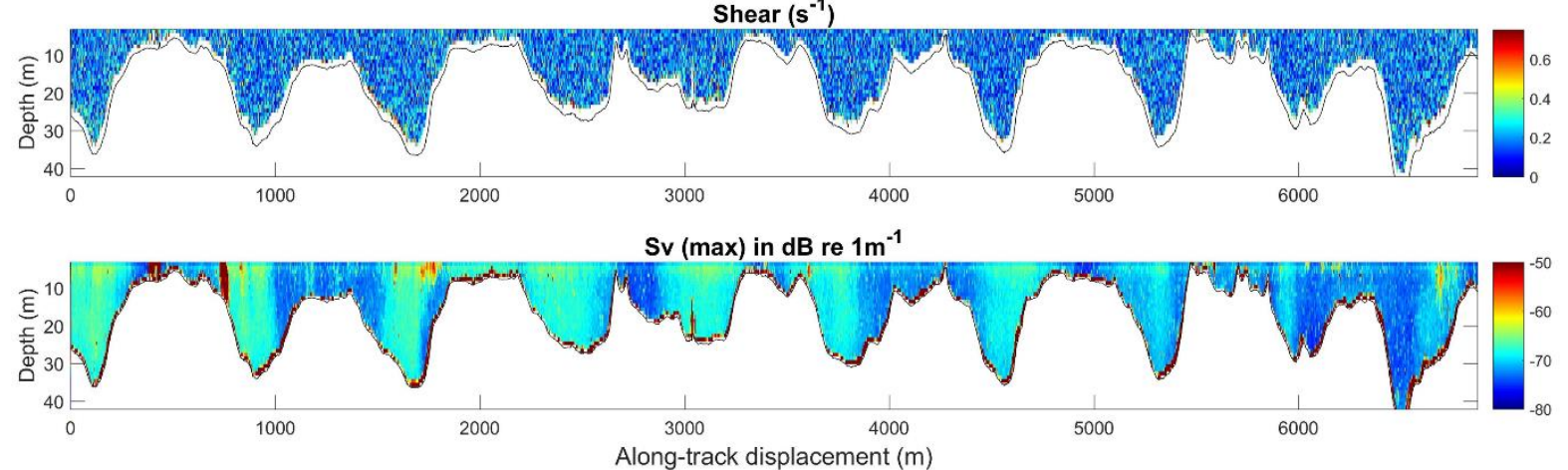

302

b) Northward Velocity $\left(\mathrm{ms}^{-1}\right)$

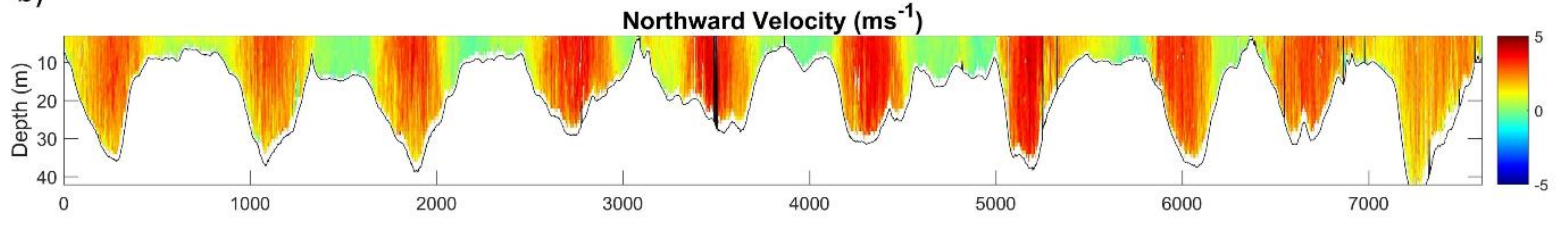

Eastward Velocity $\left(\mathrm{ms}^{-1}\right)$
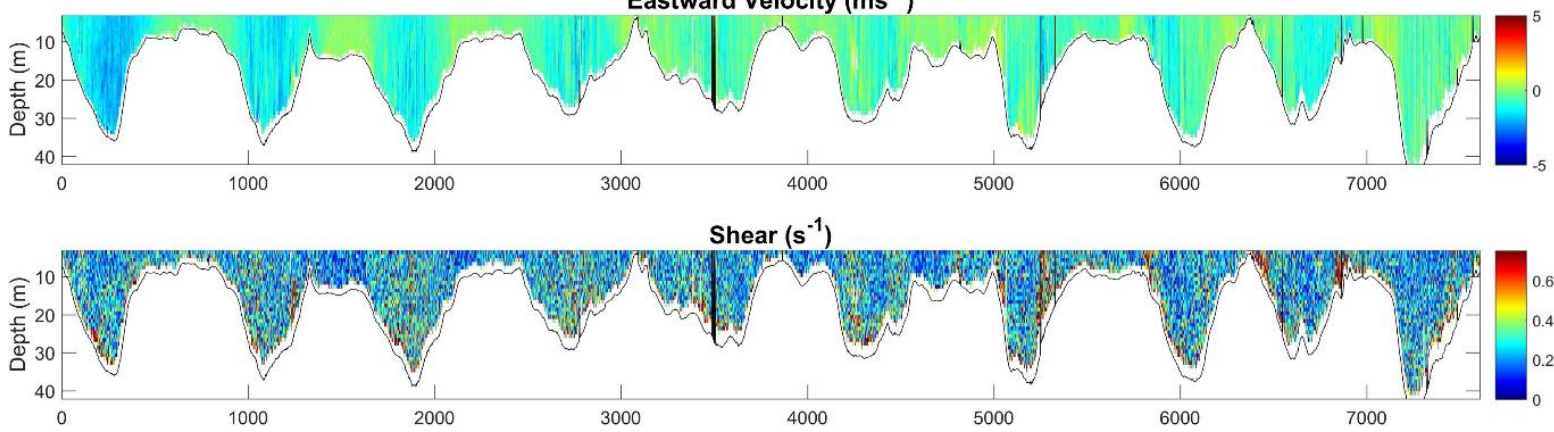

Sv $(\max )$ in $\mathrm{dB}$ re $1 \mathrm{~m}^{-1}$

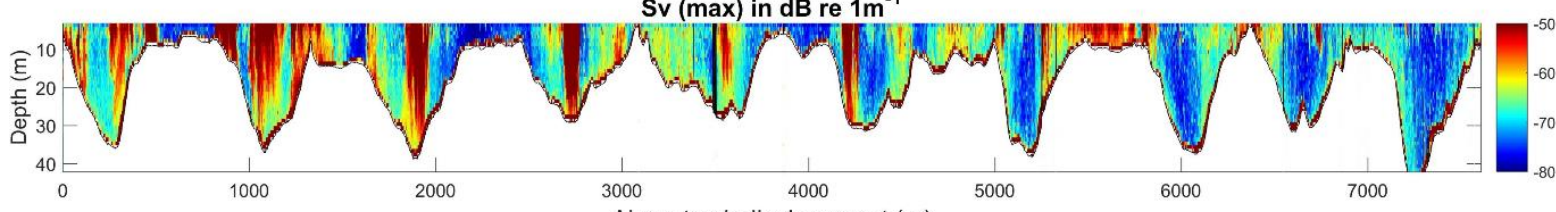

303 Figure 3: Vertical sections recorded by the ADCP along an entire transect during low water slack (a; Transect 1, spring tidal survey on 20 October 2016, 41min duration) and peak flood tide (b; Transect 4, spring tidal survey on 20 October 2016, 48 min duration), respectively. Note, the black vertical line at $3500 \mathrm{~m}$ along-track distance indicates short-term data loss. 

condition. For instance, during periods of weak flow, higher values of $S v_{\max }$ were typically associated with the central channel indicating residual turbulence may have held material in the water column, such as micro-bubbles entrained from the surface and sediment re-suspended from the bed. During peak flow, regions of extremely high $S v_{\max }$ were found extending from the surface down towards the seabed in the central part of the channel, supporting our assertion that Sv is an indicator of macroturbulence (entrained air) rather than plankton or fish.

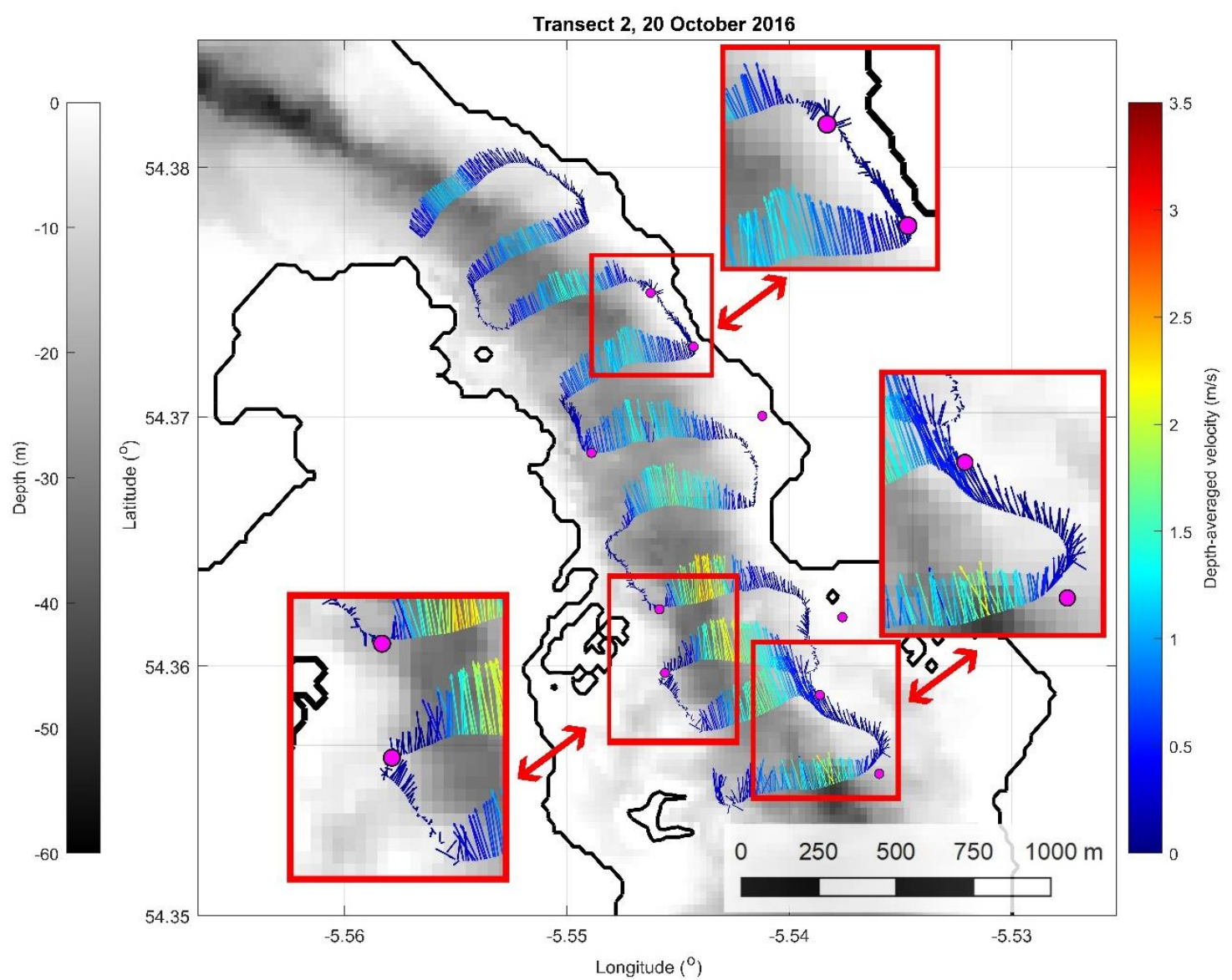

Figure 4: Typical plot of depth-averaged velocity vectors (current direction indicated by vectors and velocity magnitude by color; see color bar) during flooding tide (Transect 2; spring tidal survey on 20 October 2016). Fastest flows are observed in the mid-channel with fine-scale hydrodynamic features, such as eddies, visible around the edges of the channel (red inserts). Filled dots mark seal sightings corrected for range and bearing.

There was a clear rectilinear flow pattern in the channel with flow vectors aligned with the mean longitudinal direction of the central part of the channel. However, there was more variability in the direction of the weaker flows in the shallow areas of the channel. This became apparent when 
320 visualizing velocity vectors showing local flow reversals towards the edges of the channel (Fig. 4).

321 These reversals correspond to the presence of eddies and other turbulent features being more

322 pronounced, relative to the magnitude of the local mean flow, in these shallow areas. Finally, there

323 was no evidence for vertical stratification due to temperature $\left(T^{\circ} \mathrm{C}=13.53(\mathrm{SD}=0.14)\right.$ or salinity

324 (34.15 PSU (SD=0.13) in the mid-channel as identified by the CTD stations.

\subsection{Seal at-sea distribution}

\subsubsection{Observational Surveys}

The total number of seal sightings was 34 (23 grey and 11 harbour seals) during the spring and 18 (14 grey and 4 harbour seals) during the neap tidal survey, respectively, totaling 52 sightings. Overall, the mean number of seals sighted during each transect was $3.3(S D=2.1)$, ranging from $0-9$ observations. The spatio-temporal distribution and numbers of seal sightings is shown in Figure 5 and Table 1, while the spatial distribution of selected, ADCP-derived variables is plotted in Figure 6. 
Table 1: Detailed transect information during both the spring (20 October 2016) and neap (28 October 2016) tidal survey, in the Strangford Narrows. Sea State $(=0-1)$ and Visibility $(6-10 \mathrm{~km})$ were constant for all transects. Transects used for pinniped observations are highlighted in bold. Approximate tidal state is indicated with hours after low water (LW) and high water (HW).

\begin{tabular}{|c|c|c|c|c|c|c|c|}
\hline Date & $\begin{array}{l}\text { Transect } \\
\text { number }\end{array}$ & $\begin{array}{c}\text { Transect } \\
\text { start time } \\
\text { (GMT) }\end{array}$ & $\begin{array}{c}\text { Transect } \\
\text { end time } \\
\text { (GMT) }\end{array}$ & $\begin{array}{c}\text { Transect } \\
\text { Duration } \\
\text { (min) }\end{array}$ & $\begin{array}{c}\text { Observer } \\
\text { Effort }\end{array}$ & $\begin{array}{c}\text { \# Seal } \\
\text { Encounters }\end{array}$ & $\begin{array}{r}\text { Tidal State } \\
\text { (approx.) }\end{array}$ \\
\hline $20-10-16$ & 1 & $9: 20$ & $10: 01$ & $0: 41$ & OFF & NA & LW \\
\hline $20-10-16$ & 2 & $10: 20$ & 11:09 & $0: 49$ & ON & 9 & $L W+1$ \\
\hline $20-10-16$ & 3 & $11: 20$ & $12: 08$ & $0: 48$ & ON & 3 & $L W+2$ \\
\hline $20-10-16$ & 4 & $12: 20$ & $13: 07$ & $0: 47$ & ON & 6 & $L W+3$ \\
\hline $20-10-16$ & 5 & $13: 22$ & $14: 04$ & $0: 42$ & ON & 3 & $L W+4$ \\
\hline $20-10-16$ & 6 & $14: 20$ & $15: 06$ & $0: 46$ & ON & 5 & $L W+5$ \\
\hline $20-10-16$ & 7 & $15: 22$ & $16: 02$ & $0: 40$ & ON & 4 & HW \\
\hline $20-10-16$ & 8 & $16: 21$ & $17: 03$ & $0: 42$ & ON & 2 & HW +1 \\
\hline $20-10-16$ & 9 & $17: 19$ & $18: 13$ & $0: 54$ & ON & 2 & HW +2 \\
\hline $20-10-16$ & 10 & $18: 35$ & $19: 21$ & $0: 46$ & OFF & NA & $\mathrm{HW}+3$ \\
\hline $20-10-16$ & 11 & $19: 35$ & $20: 17$ & $0: 42$ & OFF & NA & $\mathrm{HW}+4$ \\
\hline $20-10-16$ & 12 & $20: 32$ & $21: 13$ & $0: 41$ & OFF & NA & $\mathrm{HW}+5$ \\
\hline $28-10-16$ & 1 & $6: 22$ & $7: 10$ & $0: 48$ & OFF & NA & LW +1 \\
\hline $28-10-16$ & 2 & $7: 21$ & $8: 04$ & $0: 43$ & OFF & NA & $\mathrm{LW}+2$ \\
\hline $28-10-16$ & 3 & $8: 23$ & 9:02 & 0:39 & ON & 2 & $L W+3$ \\
\hline $28-10-16$ & 4 & $9: 20$ & $10: 02$ & $0: 42$ & ON & 1 & $L W+4$ \\
\hline $28-10-16$ & 5 & $10: 20$ & 11:02 & $0: 42$ & ON & 2 & $L W+5$ \\
\hline $28-10-16$ & 6 & $11: 20$ & 11:59 & 0:39 & ON & 4 & HW \\
\hline $28-10-16$ & 7 & $12: 20$ & $13: 00$ & $0: 40$ & ON & 0 & HW +1 \\
\hline $28-10-16$ & 8 & $13: 31$ & $14: 16$ & $0: 45$ & ON & 3 & $H W+2$ \\
\hline $28-10-16$ & 9 & $14: 38$ & $15: 17$ & 0:39 & ON & 2 & $\mathrm{HW}+3$ \\
\hline $28-10-16$ & 10 & $15: 40$ & $16: 14$ & $0: 34$ & ON & 4 & $H W+4$ \\
\hline $28-10-16$ & 11 & $16: 35$ & $17: 08$ & $0: 33$ & OFF & NA & $\mathrm{HW}+5$ \\
\hline $28-10-16$ & 12 & $17: 25$ & $18: 10$ & $0: 45$ & OFF & NA & LW \\
\hline
\end{tabular}




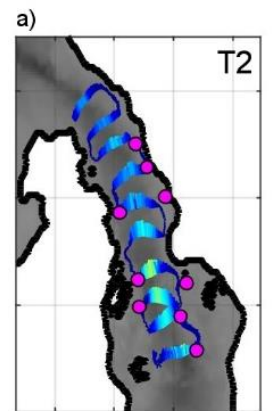

Flooding Tide Start

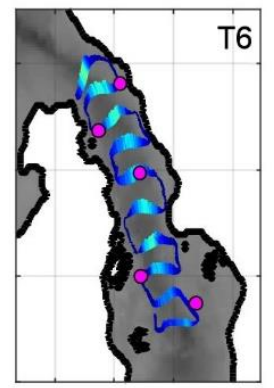

Flood Tide (incl. High Water)
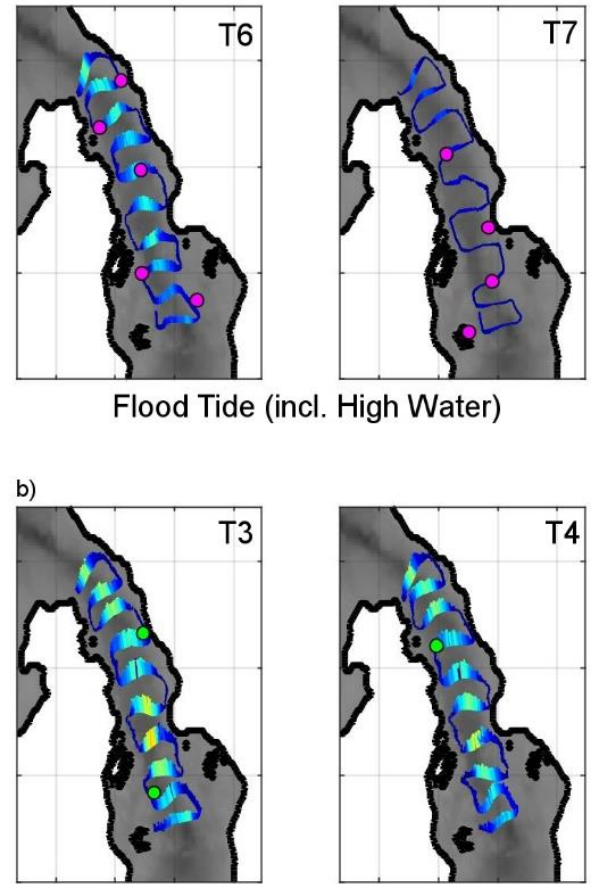

345

Flooding Tide End
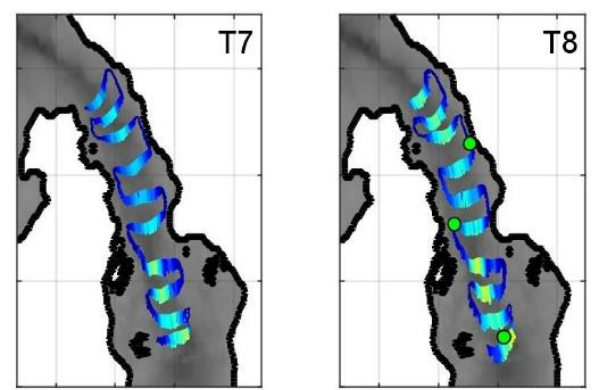

Ebbing Tide End

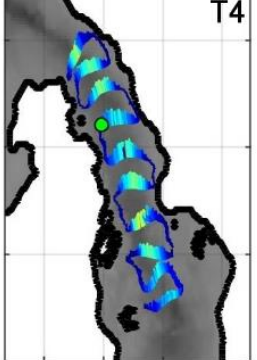

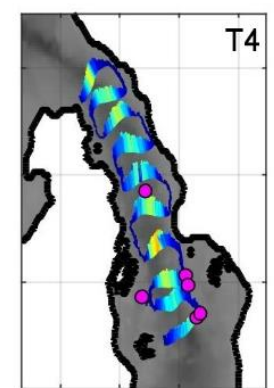

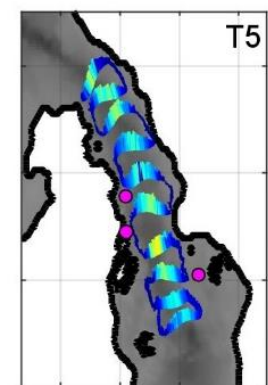

Flooding Tide End

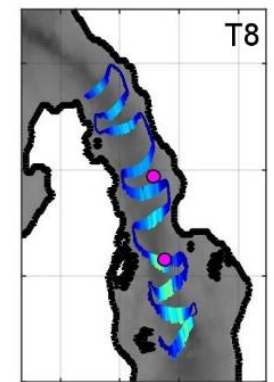

T8

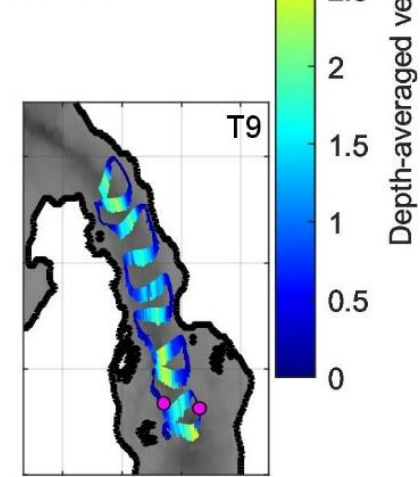

Ebbing Tide Start

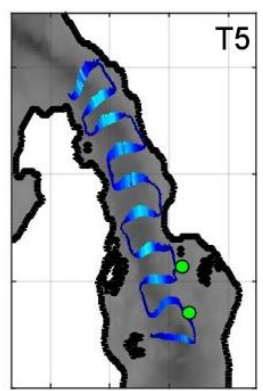

Flood Tide (incl. High Water)
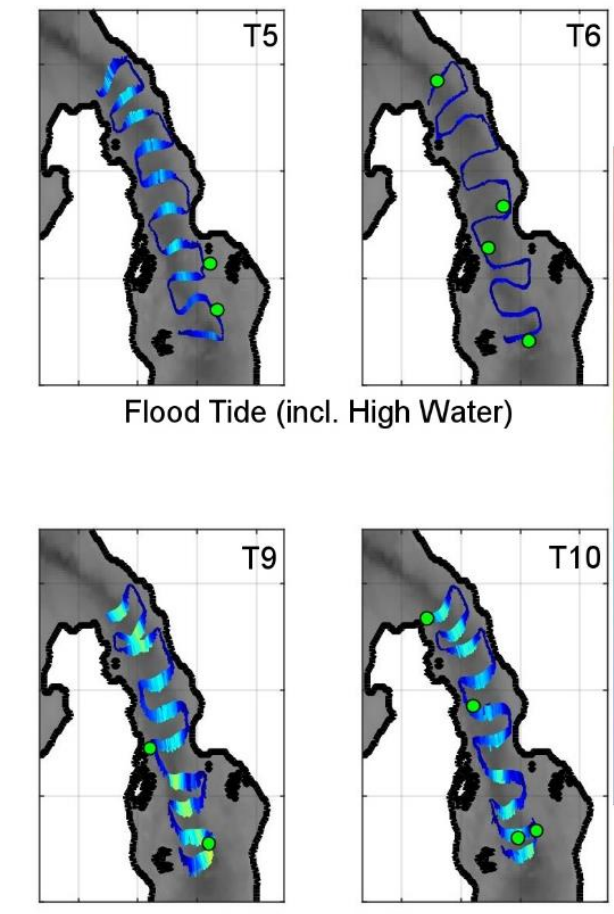

T6

Ebbing Tide End

Figure 5: Depth-averaged velocity vectors (current direction and strength) and seal sightings corrected for distance and bearing during transects of the spring (20 October 2016) (a) and neap (28 October 2016) (b) tidal survey, respectively. 

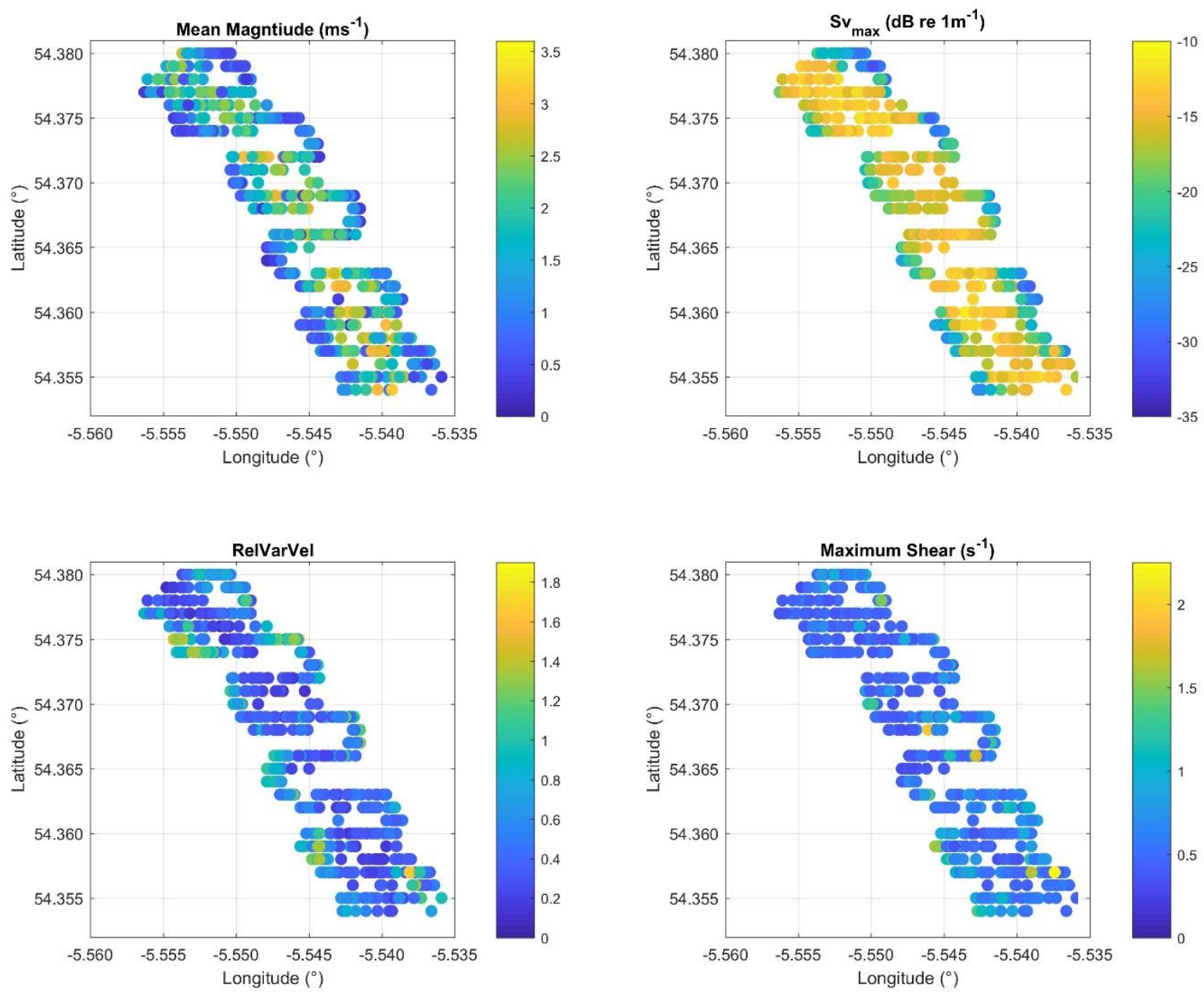

Figure 6: Plots of the spatial patterns of the dynamic variables applied in GAM models derived from concurrent ADCP measurements along all transects.

\subsubsection{Commonly-used Explanatory Variables:}

Significant relationships were only seen with $M 2 H T\left(d f=1.46, \chi^{2}=4.95, p=0.03\right)$ and $M a g(d f=$ $\left.1, \chi^{2}=7.96, p<0.01\right)$, although the relative influence of these factors differed. The probability of encountering seals per minute showed a relatively strong and negative relationship with Mag, with effect sizes indicating that encounters were 7.35 times more likely in the slowest currents (Fig. 7). Whereas across all effort transects, current magnitude values ranged from $0.19-3.41 \mathrm{~ms}^{-1}$, seals were encountered, on average, in magnitude fields of $1.15 \mathrm{~ms}^{-1}$ (SD=0.75) (Fig. S2, Supplementary Information). This further corresponds to the majority (77\%) of seal encounters associated with the edges of the channel along the $20 \mathrm{~m}$ depth contour (Fig. S3, Supplementary Information), characterized by weaker flow velocities compared to the mid-channel (Fig. 5). During slack water, 

tide (Fig. 7).
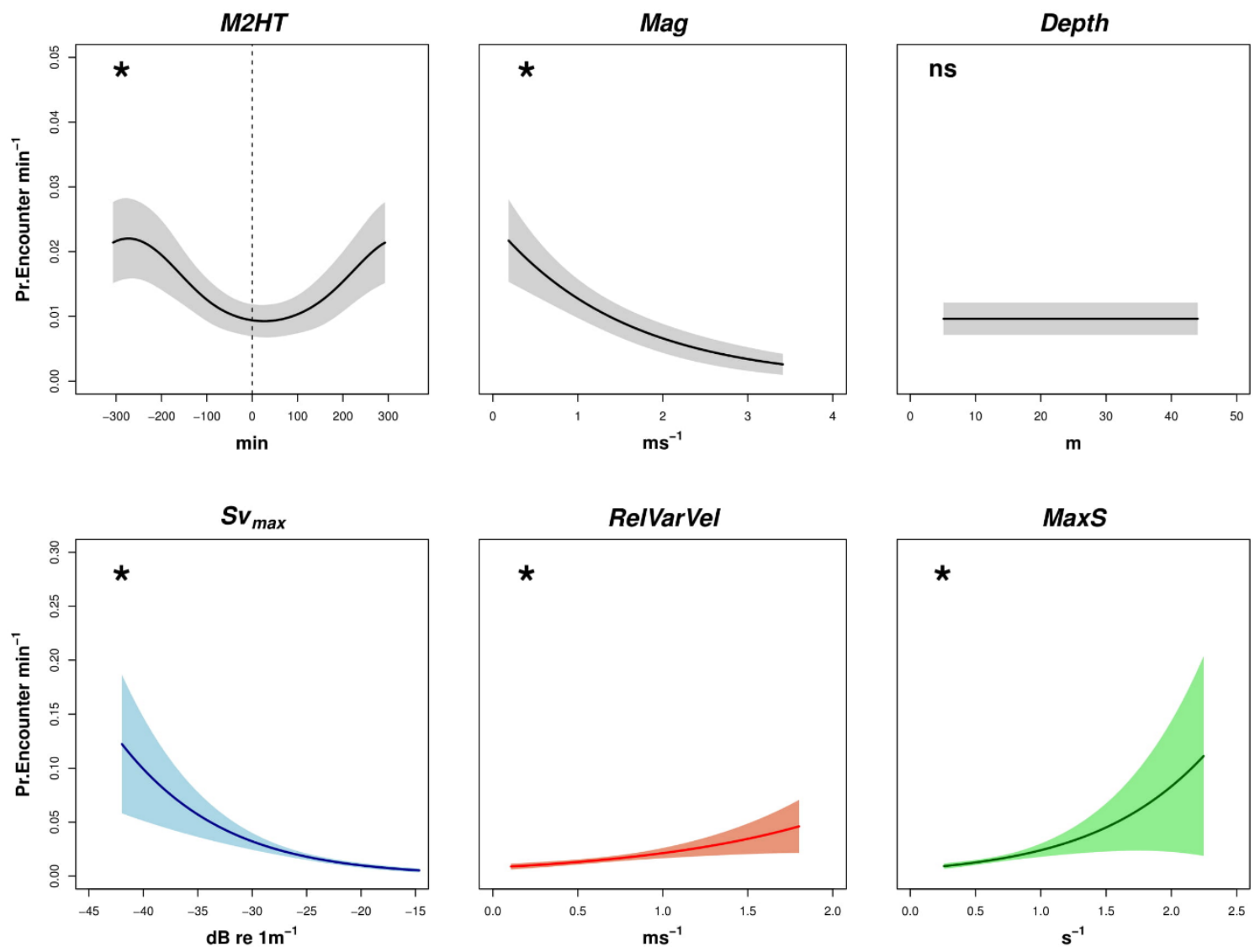

365

Figure 7: Modelled relationships between the probability of detecting seals per minute and environmental variables.

Relationships (standard errors are indicated by shading around lines) were estimated using generalised additive models

(GAMs). Different colours indicate different models. Minutes to High Tide (M2HT), depth-averaged current magnitude

$(\mathrm{Mag})$ and depth were modelled together in a single multivariate model. Maximum backscatter $\left(S v_{\max }\right)$, mean relative statistical significance $(*)$ or insigificance (ns) are indicated for each model.

\subsubsection{Novel Explanatory Variables}

Whilst all explanatory variables were significant $\left(\operatorname{MaxS} d f=1, \chi^{2}=5.13, p=0.24 ;\right.$ RelVarVel $d f=$ $\left.1, \chi^{2}=4.46, p=0.35 ; S v_{\max } \mathrm{df}=1, \chi^{2}=13.6, p<0.01\right)$, large differences in effect sizes were seen. in areas characterized by weaker acoustic backscatter (more negative values) (Fig. 7), 

corresponding to the edges of the channel (Fig. 3\&6). MaxS had the second highest influence: the probability of encountering seals was 11.04 times more likely during times of maximum vertical shear (Fig. 7). Finally, RelVarVel had the lowest influence: the probability of encountering seals was 4.20 times more likely in areas characterized by eddies, prevalent along the edges of the channel (Figs 6\&7).

\section{Discussion} This is the first study to explore at-sea pinniped distribution patterns with concurrently collected fine-scale oceanographic measurements within a tidal channel. We (1) used vesselmounted ADCP transects to characterize spatial and temporal variations in hydrodynamics within a tidal channel; (2) identified several hydrodynamic metrics (macro-turbulence 'SV $v_{\text {max }}$, eddies 'RelVarVel', and shear 'MaxS') which could have ecological relevance for mobile predators using these dynamic habitats and (3) showed that one of these metrics $\left(S v_{\max }\right)$ had more influence than a combination of more commonly-used variables (current magnitude ('Mag'), time to high water ('M2HW') and depth) to detect predator associations. In combination, these results demonstrate the efficacy of our survey approach to enhance environmental management at potential MRE sites by showing the influence of tide-topographic processes on marine predator occupancy patterns. mammal surveys with concurrent fine-scale ADCP measurements, is novel within energetic sites. Comparative approaches combined boat-based predator surveys with moored ADCP data (Scott et al., 2013), linked sightings with spatially-averaged ADCP data (IJsseldijk et al., 2015), or used landbased visual surveys combined with ADCP transects (Jones et al., 2014). This is not only the first study of its kind on pinnipeds, but it also investigates concurrent tidal dynamics and processes on comparable spatial scales to the sightings. Our approach may be highly informative within tidal energy sites with only little available baseline data but could equally be adopted for other predator distribution studies. For, instance, the fine-scale characterization and visualization of water column characteristics and the quantification of physical structures through metrics could provide 
oceanographic context to telemetry studies or passive and active surveys to gain a more in-depth ecological understanding of animal distributions.

\subsection{Hydrodynamic forcing in the main channel}

406

407

408

409

410

Tidal streams are highly dynamic environments and the longevity and predictability of hydrodynamic features can vary substantially, from fine spatio-temporal scales of meters and seconds (e.g. bathymetry induced kolk-boils, back-eddies) to larger scale (kilometers and hours) tidally-induced water movements. Here, we describe evidence of ADCP-derived metrics potentially influencing seal distribution in the Narrows. The following discussion focusses on the underlying hydrodynamics and physical structures arising during peak flows and provides an indication of the ecological significance of seal occupancy patterns observed.

During periods of peak flow, seal sightings in the Narrows were concentrated along the periphery of the highest flows, thereby avoiding the mid-channel and showing a preference for the edges of the tidal stream (Figs. 4,5 and 7). The main flow in the mid-channel showed the highest current speeds (depth-averaged current magnitude exceeded $4.5 \mathrm{~ms}^{-1}$, see Figs. S4a and S4b, Supplementary Information) and was dominated by macro-turbulence as evidenced by the increased acoustic backscatter in this region during peak flow (Fig. 3b, and Fig. S5, Supplementary Information). These regions of high backscatter are most likely clouds of micro-bubbles entrained at the surface by coherent turbulent structures or "boils" and distributed throughout the water column by strong turbulent mixing (Nimmo-Smith et al., 1999).

Marine predators performing pursuit diving of their prey are likely to forage in environments where controlled diving can be maintained while maximizing foraging efficiency, limiting extensive usage of the fastest-flowing currents within a tidal stream (Ladd et al., 2005; Waggitt et al., 2016a). Pinnipeds mostly forage by pursuing benthic or pelagic fish with an average maximum bottom swim speed for harbour seals of $2.16( \pm 0.62) \mathrm{ms}^{-1}$ (Lesage et al. 1999). Flows in the mid-channel exceeded these swimming speeds by a factor of two, imposing a metabolic cost associated with maintaining or 
re-gaining control following burst dives in faster flows (unless travelling passively or "bottling" with the current). In addition to the high current speeds, acoustic backscatter in the mid-channel, including macro-turbulence extending down from the surface and sediment re-suspension near the bed, could impair visual and auditory predatory cues. Therefore, foraging excursions into areas of strong mixing are likely to be temporally limited, restricting sightings in the mid-channel in this study. However, when comparing our observations with previous harbour seal telemetry studies in the Narrows, patterns are in accordance. It was found that seals preferentially transited the midchannel during periods of slack tide (Sparling et al., 2017), and the spatial concentration of dive density in the mid-channel was limited to periods when flow speeds were less than $1 \mathrm{~ms}^{-1}$ (Wood et al. 2016). Finally, the presence of seals in the mid-channel during slack water indicates that depth is not a driver of seal distribution patterns within the Narrows (Fig. 7).

\subsection{Fine-scale physical features at the edges of the channel}

Pinniped at-sea distribution was largely associated with the edges of the tidal channel (Fig.

5). The probability of encountering seals was estimated to be 22.23 times more likely in these areas characterized by weaker levels of macro-turbulence (Fig. 7). The edges were further associated with eddies, minimum current speeds and a higher variation in vertical shear (Figs 4 \& 6). All these dynamic metrics increased the probability of seal encounters (Fig. 7), justifying further discussion on the hydrodynamic forcing potentially underlying edge-associations.

Seal occupancy patterns during periods of fast flows observed in this study show a high degree of similarity to seal telemetry findings from the Narrows as noted above. During peak flows (current speeds $>2 \mathrm{~ms}^{-1}$ ), it was shown that seal dive density was concentrated at the edges of the channel, on the periphery of the highest flows (Wood et al., 2016). The apparent use of low-energy environments neighboring fast flows is in accordance with marine mammal use of tidal streams elsewhere. At the Scottish West Coast, harbour porpoises Phocoena phocoena have been found to spend most of their time in relatively low-energy environments adjacent to the narrow, turbulent 
strait of the Gulf of Corryvreckan (Benjamins et al., 2016). Lower current speeds and local flow reversals corresponding to the presence of eddies in the shallow areas of the Narrows may also increase foraging success. For instance, in the Bay of Fundy tidal stream, Canada, cetaceans Balaenoptera physalus and B. acutorostrata exhibited a consistent preference for eddy fields suggesting preferred foraging along predictably occurring island wake features to exploit prey aggregations retained among these eddies (Johnston et al., 2005; Johnston \& Read 2007). the largest difference between the fast-moving surface and slower near-bed flows, such as near the edges of the tidal stream (Fig. 7). The increased vertical shear associated with the shallow edges of the mid-channel may result in a combination of both prey being less likely to cross these areas (Čada et al. 2006), and seals being able to make use of aggregated prey in these areas while maintaining controlled diving (Johnston et al. 2005).

In addition, increased seabed roughness along the edges of the Narrows' mid-channel, associated with bedrock reef and extended kelp beds, may have also influenced seal presence along foraging.

\subsection{ADCP-derived acoustic backscatter and future directions}

ADCPs can determine the intensity of received echoes (total acoustic backscattering or echo intensity) over a finite volume which can be converted to mean-volume backscattering strength (Sv in dB; a logarithmic measure of scattering intensity) (Brierley et al. 1998). Such ADCP-derived quantifications of echo intensity can give information on mid-water, bio-physical targets such as the presence of dense scattering layers, including zooplankton and/or fish (Brierley et al. 1998; Deines 1999; Demer et al. 2000; Zedel \& Cyr-Racine 2009). Applying Deines' (1999) equation, backscatter

477 calculations accounted for time-varying gain, absorption loss, transmit pulse length and beam- 
specific sensitivity coefficients, making it a more robust measure compared to raw echo intensity which can be more easily extracted from ADCP data. In this study, backscatter ( $\left.S v_{\max }\right)$ was used as an indicator for surface bubble entrainment resulting from macro-turbulence as well as sediment resuspension near the bed. The scattering could not be identified as being of biological origin in the absence of acoustic multi-frequency techniques, although the backscatter patterns were more characteristic of entrained bubbles. Understanding foraging opportunities for top predators in such dynamic environments requires the assessment of real-time prey landscapes and the reliable isolation of biological targets in highly turbulent environments (Lavery et al. 2009; Fraser et al., 2017).

Additionally, prey behavior may be similarly influenced by hydrodynamic forcing. High current speeds largely exceeding most fish cruising swim speeds (generally not exceeding $2 \mathrm{~ms}^{-1}$; Videler \& Wardle 1991) in the mid-channel during peak flows may equally impose a metabolic cost to prey unless they actively seek the channel as a means of transport. Further, strong vertical turbulent conditions and high flows in the mid-channel could provide a mechanism to disorient prey and may impact on school cohesion (Zamon 2001; Liao 2007; Robinson et al. 2007). This would increase vulnerability to predators as harbour seal foraging success on schooling fish has been shown to be increased following school break-up, when a small group or a single prey item is separated, thus avoiding the confusion effect of the school (Kilian et al. 2015). Finally, patches of high vertical shear were found near the bed in the central part of the channel and fish may also avoid this part of the tidal stream during strong flows to avoid vertical displacement as sudden changes in pressure may lead to barotrauma-related injuries (Brown et al. 2009).

Future studies in the Narrows would highly benefit from the collection of multi-frequency acoustic backscatter data (e.g. EK 80/AZFP echosounder data) to help distinguish physical from biological sources of scattering (using $\mathrm{dB}$ difference techniques) and to capture spatio-temporal patterns in prey variability. The combination of hydroacoustic tools (ADCPs and calibrated echosounders) could help explore the mechanisms underlying prey behavior in the Lough following 
the extraction of fish and water velocities (Zedel \& Cyr-Racine 2009) to eventually understand the entire suite of bio-physical drivers underlying seal habitat use in the Narrows.

\subsection{Conclusion and implications}

The novelty of our approach lies in the determination of fine-scale physical metrics influencing predator occupancy patterns previously not considered in these extremely energetic habitats. The use of ADCPs in combination with other survey methodologies is still inadequately represented given its potential value in understanding a species' behavioral ecology. Our approach can be adapted to other tidal energy sites, specifically where baseline data is limited, to inform the environmental impact process from the start. It appears to be one of the most practical and costeffective approaches to streamline the EIA process in the early stages of the consenting process. Baseline studies of this kind are necessary to detect trends and to determine the spatial scales at which to further investigate more detailed predator behavior within these energetic environments. Developers tasked with undertaking a series of marine mammal sighting surveys as part of EIAs at MRE sites may adopt this methodological approach. Repeat-transect surveys of this kind allow to simultaneously inform hydrodynamic and marine mammal site characterization, therefore maximizing resources (data quality vs survey costs) allocated to EIAs. An increased number of transects (ideally during different times of the year) could improve the resolution often required for EIAs, such as applying the detection function to obtain animal density and abundance estimates, whilst also providing more detailed information on seasonal variability in flows and predator associations.

Our results showed that on average, seals were encountered in current magnitude fields of $1.15 \mathrm{~ms}^{-1}(\mathrm{SD}=0.75)$ and avoided areas of extreme acoustic backscatter, such as the mid-channel during peak flows. This may have implications for tidal energy site selection as turbines are generally placed within more predictable environments characterized by fast $\left(>2 \mathrm{~ms}^{-1}\right)$, uni-directional flows and lower degrees of terrain ruggedness (to reduce bathymetry-induced turbulence and issues with 
foundation deployment). Seals sighted in the mid-channel, areas where such characteristics would be fulfilled, were highest during slack water when tidal turbines are less likely to be operating at full capacity (or at all) and therefore risk from interactions (e.g. collision) is deemed to be low.

532

\section{Authors contributions}

LL and LK conceived the ideas and designed the study; LK coordinated data acquisition and managed the project. LL collected the data and LL, WAMNS and JJW performed the analysis and interpreted the results. LL drafted the manuscript. All authors contributed critically to the drafts and gave final approval for publication.

\section{Acknowledgements}

This study is part of the PowerKite project which has received funding from the European Union's Horizon 2020 research and innovation programme under grant agreement No 654438. James which is funded by the Natural Environment Research Council and the Department for Environment, Food \& Rural Affairs (NERC/DEFRA). We would particularly like to acknowledge the support given by Pál Schmitt during data collection. We also wish to thank Jeremy Rogers, Simon Rogers and Oliver Rogers from Cuan Marine Services for boat time, seamanship and their in-depth knowledge of the Narrows necessary for this study's survey methodology. Finally, we'd like to thank Laura Hobbs and Andrew S. Brierley for advice on backscatter calculations. The authors declare no conflict of interest.

\section{Data accessibility}

549 The data used in this manuscript will be deposited in the Dryad Digital Repository.

\section{References}

551 Benjamins, S., Dale, A.C., Hastie, G., Waggitt, J.J., Lea, M.-A., Scott, B. \& Wilson, B. (2015a) Confusion Reigns? A Review of Marine Megafauna Interactions with Tidal-Stream Environments. Oceanography and Marine Biology: An Annual Review, 53, 1-54. 
Benjamins, S., Dale, A., Van Geel, N. \& Wilson, B. (2016) Riding the tide: Use of a moving tidal-stream habitat by harbour porpoises. Marine Ecology Progress Series, 549, 275-288.

559

560

561

Benjamins, S., van Geel, N., Hastie, G., Elliott, J. \& Wilson, B. (2017) Harbour porpoise distribution can vary at small spatiotemporal scales in energetic habitats. Deep Sea Research Part II: Topical Studies in Oceanography, 141, 191-202.

Buckland, S.T., Anderson, D.R., Burnham, K.P., Laake, J.L., Borchers, D.L. \& Thomas, L. (2001) Introduction to Distance Sampling: Estimating Abundance of Biological Populations.

Brierley, A.S., Brandon, M.A. \& Watkins, J.L. (1998) An assessment of the utility of an acoustic Doppler current profiler for biomass estimation. Deep Sea Research Part I: Oceanographic Research Papers, 45, 1555-73.

Brown, R.S., Carlson, T.J., Welch, A.E., Stephenson, J.R., Abernethy, C.S., Ebberts, B.D., Langeslay, M.J., Ahmnan, M.L., Feil, D.H., Skalski, J.R. \& Townsend, R.L. (2009). Assessment of barotrauma from rapid decompression of depth- acclimated juvenile Chinook salmon bearing radiotelemetry transmitters. Transactions of the American Fisheries Society 138, 1285-1301.

Čada, G., Loar, J., Garrison, L., Fisher, R., Jr \& Neitzel, D. (2006). Efforts to reduce mortality to hydroelectric turbine- passed fish: locating and quantifying damaging shear stresses. Environmental Management 37, 898-906.

Deines, K.L. (1999) Backscatter estimation using Broadband acoustic Doppler current profilers. Proceedings of the IEEE Sixth Working Conference on Current Measurement (Cat. No.99CH36331), 1-5.

Demer, D.A., Barange, M. \& Boyd, A.J. (2000) Measurements of three-dimensional fish school velocities with an acoustic Doppler current profiler. Fisheries Research, 47, 201-214.

Embling, C.B., Illian, J., Armstrong, E., van der Kooij, J., Sharples, J., Camphuysen, K.C.J. \& Scott, B.E. (2012) Investigating fine-scale spatio-temporal predator-prey patterns in dynamic marine ecosystems: a functional data analysis approach. Journal of Applied Ecology, 49, 481-492. 
Epler, J., Polagye, B. \& Thomson, J. (2010) Shipboard acoustic Doppler current profiler surveys to assess tidal current resources. OCEANS 2010, MTS/IEEE Seattle, USA.

Evans, P., Armstrong, S., Wilson, C., Fairley, I., Wooldridge, C. \& Masters, I. (2013) Characterisation of a Highly Energetic Tidal Energy Site with Specific Reference to Hydrodynamics and Bathymetry. In Proceedings of the 10th European wave and tidal energy conference (EWTEC 2013).

Fong, D.A. \& Monismith, S.G. (2004) Evaluation of the accuracy of a ship-mounted, bottom-tracking ADCP in a near-shore coastal flow. Journal of Atmospheric and Oceanic Technology, 21, 1121-1128.

Fox, C.J., Benjamins, S., Masden, E. \& Miller, R. (2017) Challenges and opportunities in monitoring the impacts of tidal-stream energy devices on marine vertebrates. Renewable and Sustainable Energy Reviews, 81, Part 2, 1926-1938

Fraenkel, P. (2004) Marine Current Turbines: an emerging technology. Paper for Scottish Hydraulics Study Group Seminar in Glasgow on 19 March 2004 Renewable Energy - Hydraulic Applications - Theory and Practice, 1-10.

Fraser, S., Nikora, V., Williamson, B.J. \& Scott, B.E. (2017) Automatic active acoustic target detection in turbulent aquatic environments. Limnol. Oceanogr. Methods, 15, 184-199.

Goddijn-Murphy, L., Woolf, D.K. \& Easton, M.C. (2013) Current patterns in the inner sound (Pentland Firth) from underway ADCP data. Journal of Atmospheric and Oceanic Technology, 30, 96-111.

Harwood, J., Stokes, K. (2003) Coping with uncertainty in ecological advice: lessons from fisheries. Trends Ecol Evol 18, 617-22.

Hastie, G.D., Russell, D.J.F., Benjamins, S., Moss, S., Wilson, B. \& Thompson, D. (2016) Dynamic habitat corridors for marine predators; intensive use of a coastal channel by harbour seals is modulated by tidal currents. Behavioral Ecology and Sociobiology, 70, 2161-2174.

IJsseldijk, L. L., Camphuysen, K. C. J., Nauw, J. J., \& Aarts, G. (2015). Going with the flow: Tidal influence on the occurrence of the harbour porpoise (Phocoena phocoena) in the Marsdiep area, The Netherlands. Journal of Sea Research, 103, 129-137. 
Jeffcoate, P., Whittaker, T., Boake, C. \& Elsäßer, B. (2016) Field tests of multiple 1/10 scale tidal turbines in steady flows. Renewable Energy, 87, 240-252.

Johnston, D.W. \& Read, A.J. (2007) Flow-field observations of a tidally driven island wake used by marine mammals in the Bay of Fundy, Canada. Fisheries Oceanography, 16, 422-435.

Johnston, D.W., Thorne, L.H. \& Read, A.J. (2005) Fin whales Balaenoptera physalus and minke whales Balaenoptera acutorostrata exploit a tidally driven island wake ecosystem in the Bay of Fundy. Marine Ecology Progress Series, 305, 287-295.

Jones, A.R., Hosegood, P., Wynn, R.B., De Boer, M.N., Butler-Cowdry, S. \& Embling, C.B. (2014) Fine-scale hydrodynamics influence the spatio-temporal distribution of harbour porpoises at a coastal hotspot. Progress in Oceanography, 128, 30-48.

Kilian, M., Dehnhardt, G., Hanke, F.D. (2015) How harbour seals (Phoca vitulina) pursue schooling herring. Mammal Biol 80, 385-389

Kregting, L. \& Elsäßer, B. (2014) A Hydrodynamic Modelling Framework for Strangford Lough Part 1: Tidal Model. Journal of Marine Science and Engineering, 2, 46-65.

Kregting, L., Elsäßer, B., Kennedy, R., Smyth, D., O’Carroll, J. \& Savidge, G. (2016) Do changes in current flow as a result of arrays of tidal turbines have an effect on benthic communities? PLOS ONE, 11, 1-14.

Ladd, C., Jahncke, J., Hunt, G.L., Coyle, K.O. \& Stabeno, P.J. (2005) Hydrographic features and seabird foraging in Aleutian Passes. Fisheries Oceanography, 14, 178-195.

Lavery, A. C., Chu, D. \& Moum, J.N. (2009) Measurements of acoustic scattering from zooplankton and oceanic microstructure using a broadband echosounder. ICES Journal of Marine Science, 67, 379-394.

Lesage, V., Hammil, M.O., Kovacs, K.M., (1999). Functional classification of harbor seal (Phoca vitulina) dives using depth profiles, swimming velocity, and an index of foraging success. Can. J. Zool. 77, 74-87.

Levin, P.S. (1991) Effects of microhabitat on recruitment variation in a Gulf of Maine reef fish. Marine Ecology Progress Series, 75, 183-189.

Liao, J.C. (2007) A review of fish swimming mechanics and behaviour in altered flows. Philosophical 
Lu, Y. \& Lueck, R.G. (1999) Using a broadband ADCP in a tidal channel. Part I: Mean flow and shear. Journal of Atmospheric and Oceanic Technology, 16, 1556-1567.

Nimmo-Smith, W.A.M., Thorpe, S.A. \& Graham, A. (1999) Surface effects of bottom-generated turbulence in a shallow tidal sea. Nature, 400, 251-254.

Polagye, B. \& Thomson, J. (2013) Tidal energy resource characterization: methodology and field study in Admiralty Inlet, Puget Sound, US. Proceedings of the Institution of Mechanical Engineers, Part A: Journal

R Core Team (2014) R: A Language and Environment for Statistical Computing. R Foundation for Statistical Computing, Vienna, Austria.

Robinson, C.J., Gómez-Aguirre, S. \& Gómez-Gutiérrez, J. (2007). Pacific sardine behaviour related to tidal current dynamics in Bahía Magdalena, México. Journal of Fish Biology, 71, 200-218.

Savidge, G., Ainsworth, D., Bearhop, S., Christen, N., Elsäßer, B., Fortune, F.,... \& Whittaker, T.J.T. (2014) Strangford Lough and the SeaGen Tidal Turbine. M. A. Shields, A. I. L. Payne (eds), Marine Renewable

Scott, B. E., Webb, A., Palmer, M. R., Embling, C. B., \& Sharples, J. (2013). Fine scale bio-physical oceanographic characteristics predict the foraging occurrence of contrasting seabird species; Gannet (Morus bassanus) implications of altering the hydrodynamics of the marine environment. Ocean Coast Manag, 54, 2-9 current profiler. Continental Shelf Research, 10, 589-603. 
Thomas, L., Buckland, S.T., Rexstad, E.A., Laake, J.L., Strindberg, S., Hedley, S.L., Bishop, J.R.B., Marques, T.A. \& Burnham, K.P. (2010) Distance software: Design and analysis of distance sampling surveys for estimating population size. Journal of Applied Ecology, 47, 5-14.

Videler, J.J. \& Wardle, C.S. (1991). Fish swimming stride by stride: speed limits and endurance. Reviews in Fish Biology and Fisheries 1, 23-40.

Waggitt, J.J., Cazenave, P.W., Torres, R., Williamson, B.J. \& Scott, B.E. (2016a) Predictable hydrodynamic conditions explain temporal variations in the density of benthic foraging seabirds in a tidal stream environment. ICES Journal of Marine Science, 73, 2677-2686.

Waggitt, J.J., Cazenave P.W., Torres, R., Williamson, B. \& Scott, B. (2016b) Quantifying pursuit-diving seabirds use of fine-scale physical features in tidal stream environments. Journal of Applied Ecology, 53, 16531666.

Waggitt, J.J., Dunn, H.K., Evans, P.G.H., Hiddink, J.G., Holmes, L.J., Keen, E., Murcott, B.D., Piano, M., Robins, P.E., Scott, B.E., Whitmore, J., Veneruso, G. (2017a) Regional-scale patterns in harbour porpoise occupancy of tidal stream environments. ICES Journal of Marine Science, doi:10.1093/icesjms/fsx164

Waggitt, J.J., Robbins, A.M.C., Wade, H.M., Masden, E.A., Furness, R.W., Jackson, A.C. \& Scott, B.E. (2017b) Comparative studies reveal variability in the use of tidal stream environments by seabirds. Marine Policy, 81, 143-152.

Waggitt, J.J. \& Scott, B.E. (2014) Using a spatial overlap approach to estimate the risk of collisions between deep diving seabirds and tidal stream turbines: A review of potential methods and approaches. Marine Policy, 44, 90-97.

Wilson, B., Batty, R.S., Daunt, F. \& Carter, C. (2007) Collision risks between marine renewable energy devices and mammals, fish and diving birds. Report to the Scottish Executive.Scottish Association for Marine Science, Oban, Scotland, PA37 1QA., 1-105.

Wood, J., Joy, R. \& Sparling, C. (2016) Harbor Seal - Tidal Turbine Collision Risk Models. An Assessment of Sensitivities. Prepared for PNNL / DOE by SMRU Consulting.

Woods, S. (2006) Generalized Additive Models: An Introduction with R. CRC Texts in Statistical Science. 
681 Woods, S. (2017) Mixed GAM Computation Vehicle with GCV/AIC/REML Smoothness Estimation.

682 Zamon, J.E. (2001) Seal predation on salmon and forage fish schools as a function of tidal currents in the San

683 Juan Islands, Washington, USA. Fisheries Oceanography, 10, 353-366.

684 Zedel, L. \& Cyr-Racine, F.-Y. (2009) Extracting fish and water velocity from Doppler profiler data. ICES Journal of 685 Marine Science, 66, 1846-1852.

686 